\title{
A network analysis of audiovisual affective speech perception
}

Citation for published version (APA):

Jansma, H., Roebroeck, A., \& Münte, T. F. (2014). A network analysis of audiovisual affective speech perception. Neuroscience, 256, 230-241. https://doi.org/10.1016/j.neuroscience.2013.10.047

Document status and date:

Published: 03/01/2014

DOI:

10.1016/j.neuroscience.2013.10.047

Document Version:

Publisher's PDF, also known as Version of record

Document license:

Taverne

Please check the document version of this publication:

- A submitted manuscript is the version of the article upon submission and before peer-review. There can be important differences between the submitted version and the official published version of record.

People interested in the research are advised to contact the author for the final version of the publication, or visit the DOI to the publisher's website.

- The final author version and the galley proof are versions of the publication after peer review.

- The final published version features the final layout of the paper including the volume, issue and page numbers.

Link to publication

\footnotetext{
General rights rights.

- You may freely distribute the URL identifying the publication in the public portal. please follow below link for the End User Agreement:

www.umlib.nl/taverne-license

Take down policy

If you believe that this document breaches copyright please contact us at:

repository@maastrichtuniversity.nl

providing details and we will investigate your claim.
}

Copyright and moral rights for the publications made accessible in the public portal are retained by the authors and/or other copyright owners and it is a condition of accessing publications that users recognise and abide by the legal requirements associated with these

- Users may download and print one copy of any publication from the public portal for the purpose of private study or research.

- You may not further distribute the material or use it for any profit-making activity or commercial gain

If the publication is distributed under the terms of Article $25 \mathrm{fa}$ of the Dutch Copyright Act, indicated by the "Taverne" license above, 


\section{A NETWORK ANALYSIS OF AUDIOVISUAL AFFECTIVE SPEECH PERCEPTION}

\author{
H. JANSMA, ${ }^{\mathrm{a}, \mathrm{b}}$ A. ROEBROECK ${ }^{\mathrm{b}}$ AND T. F. MÜNTE ${ }^{\mathrm{a}}$ * \\ a Department of Neurology, University of Lübeck, Lübeck, Germany \\ ${ }^{\mathrm{b}}$ Department of Cognitive Neuroscience, Faculty of Psychology \\ and Neuroscience, Maastricht University, Maastricht, \\ The Netherlands
}

\begin{abstract}
In this study we were interested in the neural system supporting the audiovisual (AV) integration of emotional expression and emotional prosody. To this end normal participants were exposed to short videos of a computer-animated face voicing emotionally positive or negative words with the appropriate prosody. Facial expression of the face was either neutral or emotionally appropriate. To reveal the neural network involved in affective AV integration, standard univariate analysis of functional magnetic resonance (fMRI) data was followed by a random-effects Granger causality mapping (RFX-GCM). The regions that distinguished emotional from neutral facial expressions in the univariate analysis were taken as seed regions. In trials showing emotional expressions compared to neutral trials univariate analysis showed activation primarily in bilateral amygdala, fusiform gyrus, middle temporal gyrus/superior temporal sulcus and inferior occipital gyrus. When employing either the left amygdala or the right amygdala as a seed region in RFX-GCM we found connectivity with the right hemispheric fusiform gyrus, with the indication that the fusiform gyrus sends information to the Amygdala. These results led to a working model for face perception in general and for AV-affective integration in particular which is an elaborated adaptation of existing models. (c) 2013 IBRO. Published by Elsevier Ltd. All rights reserved.
\end{abstract}

Key words: audiovisual speech, emotion, facial affect perception, amygdala, Granger causality.

\section{INTRODUCTION}

Audiovisual (AV) integration in the perception of speech is the rule rather than the exception. For example, the presence of congruent visual ( $\mathrm{V}$ ) information leads to a considerable improvement of intelligibility under noisy conditions (Sumby and Pollack, 1954; Schwartz et al.,

\footnotetext{
*Correspondence to: T. F. Münte, Department of Neurology, University of Lübeck, Ratzeburger Allee 160, 23538 Lübeck, Gremany. Tel: + 49-45150052925; fax: + 49-4515005457.

E-mail address: Thomas.muente@neuro.uni-luebeck.de (T. F. Münte). Abbreviations: AV, audiovisual; BOLD, blood oxygen level dependent; EMO, emotional; fMRI, functional magnetic resonance; FOV, field of view; IFG, inferior frontal gyrus; MTG, middle temporal gyrus; NEU, neutral; RFX-GCM, random effects Granger causality mapping; STS, superior temporal sulcus; V, visual; VOI, volume of interest.
}

2004; Ross et al., 2007) which can be in the range of $10 \mathrm{~dB}$. On the other hand, incongruent $\mathrm{V}$ information may induce the striking McGurk illusion (McGurk and MacDonald, 1976) during which syllables are perceived that are neither heard nor seen (e.g., percept/da/, auditory information: /ba/, visual information/ga/). This illusion suggests that AV integration during speech perception is a rather automatic process.

A number of recent studies have addressed the neural underpinnings of AV integration in speech perception and consistently found two different brain areas, the inferior frontal gyrus (IFG) and the superior temporal sulcus (STS) (Calvert et al., 2000; Calvert and Campbell, 2003; Sekiyama et al., 2003; Wright et al., 2003; Barraclough et al., 2005; Szycik et al., 2008, 2009, 2012). Interactions of the STS and IFG are captured by the AV-motor integration model of speech perception (Skipper et al., 2007). This model posits the formation of a sensory hypothesis in STS which is further specified in terms of the motor goal of the articulatory movements established in the pars opercularis of the IFG. While the advantage of $A V$ information over unimodal $A$ or $V$ information for the perception of speech is clearly established, the question arises whether bimodal AV information is also advantageous for other types of information. Indeed, it has been shown that the identity of a speaker might be recognized from both visual and auditory information but that there is a strong interaction between these kinds of information (von Kriegstein et al., 2005; Blank et al., 2011).

The topic of the present study is AV integration of affective information transmitted by the voice or face of a speaker. (Scherer, 2003) compared the recognition accuracy for vocal and facial emotions as they had been obtained in a number of studies either using unimodal vocal expression (previously reviewed by Scherer et al. (2001)) or unimodal facial expression (previously reviewed by Ekman (1994)). If one limits the analysis to studies of Western faces and voices, recognition accuracy for the emotions anger, fear, joy, sadness, disgust, and surprise ranged between $31 \%$ (disgust) and $77 \%$ (anger) for vocal emotions and between $77 \%$ (fear) and $95 \%$ (joy) for facial expressions. Thus, for both modalities recognition for most emotions is far from perfect. The question therefore arises whether the combination of both types of information will increase recognition accuracy. Indeed, a number of studies have revealed clear behavioral face-voice integration effects for affective stimuli: for example, de Gelder and 
Vroomen (2000) obtained affective ratings of facial stimuli that were morphed to represent a continuum between two facial expressions. These ratings were clearly influenced by the concurrent presentation of an affective vocalization, even under instructions to ignore the voice. A comparable effect was also obtained for ratings of affect for the vocalizations. Further research revealed that crossmodal interaction occurs even, if facial expressions are presented subliminally (de Gelder et al., 2002). In a similar vein, Collignon et al. (2008) found that the irrelevant information affected processing, even if participants were asked to ignore one sensory modality, thus further suggesting mandatory integration of visual and auditory emotional information. Further evidence for early interaction comes from electrophysiological studies. Incongruent pairings of an affective vocalization and a facial emotion have been found to evoke a negativity akin to the mismatch negativity around $180 \mathrm{~ms}$ (de Gelder et al., 1999), whereas in another study affectively congruent voice/ face pairings gave rise to an enhanced amplitude of the auditory N1 response (Pourtois et al., 2000).

Neuroimaging has been used to shed light on the functional neuroanatomy of the processing of affective facial and vocal information. Facial expressions, even when presented subliminally, have been shown to activate the amygdala with the greatest responses observed for expressions of fear (Breiter et al., 1996; Morris et al., 1996; Gelder et al., 1997; Whalen et al., 2001; Williams, 2002; Noesselt et al., 2005; Vuilleumier and Pourtois, 2007). Interestingly, robust activations for the amygdala have been observed when emotional processing is implicit, whereas explicit emotion recognition often leads to a deactivation of the amygdala (Critchley et al., 2000). Other regions that have been found with regard to the processing of facial expressions include the orbitofrontal cortex which is activated by fearful (Vuilleumier et al., 2001), angry but not sad expressions (Blair et al., 1999). The latter dissociation of the processing of angry and sad expressions has also been found for the anterior cingulate cortex (Blair et al., 1999). Adolphs (2002a,b) has summarized the imaging and lesion findings and has suggested a neuroanatomical model of affect recognition from facial expressions.

With regard to the processing of voice, the seminal study of Belin et al. (2002) suggested a prominent role of the STS. Even earlier, the amygdala has been implicated by a number of studies for the processing of affective vocalizations (Phillips et al., 1998; Morris et al., 1999). Buchanan et al. (2000) compared the detection of emotional and semantic properties of stimuli with the former giving rise to activity in the right inferior frontal lobe. Adolphs et al. (2002) found that the right frontoparietal cortex, left frontal operculum and bilateral frontal polar cortex (area 10) are critical to recognizing emotion from prosody. Investigating vocal attractiveness as a paralinguistic cue during social interactions, Bestelmeyer et al. (2012) similarly found that inferior frontal regions in addition to voice-sensitive auditory areas were strongly correlated with implicitly perceived vocal attractiveness. In an effort to distinguish the neural representation of different kinds of emotion, Ethofer et al. (2009) presented pseudowords spoken with different affective connotation (anger, sadness, neutral, relief, and joy) and subjected their functional magnetic resonance (fMRI) activations to multivariate pattern analysis. These authors successfully decoded the different vocal emotions from fMRI in bilateral voicesensitive areas.

With regard to crossmodal integration of emotional information, a first fMRI study required participants to categorize static facial expression as fearful or happy while simultaneously presented emotional vocalizations were to be ignored (Dolan et al., 2001). Activation of the left amygdala was stronger when both, facial expression and voice signaled fear, thus suggesting a role of the amygdala in the crossmodal integration of fear. Building on this early study, Ethofer et al. (2006a,b) found that the crossmodal bias observed in affective ratings of fear correlated with activity in the amygdalae. Applying the criterion of supra-additivity (i.e., the response to facevoice pairings in combination is greater than the sum of the activations to each of the modalities presented separately), Pourtois et al. (2005) delineated the middle temporal gyrus (MTG) as a core region for the crossmodal integration of a variety of emotions. While these earlier studies used static facial expressions, Kreifelts et al. (2007) employed dynamic video-clips and tested a number of different emotional expressions. The bilateral posterior STS region, which has also been highlighted for $\mathrm{AV}$ integration in general, was found to be important for affective integration in this study. In a further study (Kreifelts et al., 2009) these authors found evidence for a segregation of the STS region into a voice-sensitive region in the trunk section, a region with maximum face sensitivity in the posterior terminal ascending branch, and an AV integration area for emotional signals at the bifurcation of the STS. Similar to the present study, Klasen et al. (2011) used computer-generated emotional faces and voices to assess the neural effects of emotional congruency during an explicit emotional classification task. Congruent AV stimuli led to activation in amygdala, insula, ventral posterior cingulate, temporo-occipital, and auditory cortex, whereas incongruent stimuli gave rise to activations in frontoparietal regions as well as the caudate nucleus bilaterally.

In the present investigation we were interested in the neural system supporting the AV integration of emotional face information and emotional prosody. Normal participants were exposed to short videos of a computer-animated face voicing emotionally positive or negative words with the appropriate prosody. Facial expression was either neutral or emotionally appropriate. To reveal the neural network involved in AV integration, standard univariate analysis of fMRI data was followed by a connectivity analysis (Granger causality mapping (GCM); Roebroeck et al., 2005; Valdes-Sosa et al., 2011; Stephan and Roebroeck, 2012). GCM was introduced as it allows, similar to dynamic causal modeling (Stephan and Roebroeck, 
2012), to investigate directed influences of one brain area on others. An advantage of the particular implementation of GCM used in this paper is that no a priori model about the number of brain areas and their connections has to be used. GCM has been applied successfully to fMRI analysis in a number of studies (e.g., Formisano et al., 2002; Bressler et al., 2008; Sridharan et al., 2008). We predicted to find enhanced neural activity in the STS for emotionally appropriate relative to neutral animations and a causal influence of the auditory cortex and visual areas related to the processing of affective facial information in the STS.

\section{EXPERIMENTAL PROCEDURE}

All procedures were approved by the ethics review board of the University of Magdeburg, the affiliation of the first and last author at the time of the study. The study was performed in compliance with the Declaration of Helsinki.

\section{Participants and procedure}

The data of 14 right-handed, neurologically healthy participants with normal or corrected-to-normal visual acuity were used (8 women, age range 19-24 years). Data of six additional participants had to be discarded either due to extensive head-movements $(n=5)$ or problems with contact lenses $(n=1)$.

\section{Stimuli}

A total of 60 concrete German nouns with a positive and 60 concrete nouns with a negative affective connotation were selected from the Berlin Affective Word List (Vo et al., 2006) which comprises 2200 German words assessed by 88 normal German speaking volunteers for emotional valence (on a 7-point scale ranging from -3 to 3 ) and imageability (on a 7-point scale ranging from 1 to 7 ). Selected positive words had a mean rating of 1.83 (SD 0.38) and negative words had a mean rating of -1.83 (SD 0.35). Positive and negative words were matched for imageability (average. positive 4.52; SD 1.43; negative 4.29; SD 1.03).

Short video-clips of an animated, computergenerated, photo-realistic face with synchronized lipmovements pronouncing the words were produced using the software Maya (http://www.autodesk.com; for examples see Supplemental Material). The quality of the animations is comparable with modern special effects animations used in the film industry. The emotional expression of the computer-animated face was assessed by a group of 10 young participants (5 women, age 19-28). These were asked to rate the valence of the facial expression on a scale ranging from -5 (very negative) to +5 (very positive). Emotionally negative/positive expressions were judged to be $-3.4 / 3.1$.

The words were spoken by a professional voice actor using affective prosody that matched the emotional valence (positive or negative) of the word. Again, 10 young participants judged the emotional valence of the intonation of the actor on a scale ranging from -5 (very negative) to +5 (very positive). A mean rating of the negatively/positively spoken words of $-3.1 / 2.6$ was obtained.

The face of the animated character either showed a modulated emotional expression (henceforth: EMO) or remained neutral (NEU). In order to avoid item effects, a neutral and an emotionally modulated animation was made of each word. The participants were shown $50 \%$ of the words with a neutral animation and the remainder with an emotional animation. The animation types were counterbalanced across subjects such that each item was equally tested in both animation types.

All animations lasted $1880 \mathrm{~ms}$ corresponding to 47 video frames and were displayed with a frame rate of 25 frames per second. The animations had a resolution of $1024 \times 768$ pixels, an aspect ratio of $4: 3$, and 24 bit sample size. The corresponding audio signal had 16 -bit resolution.

Because a computer-animated face was used, it could be ensured that EMO and NEU conditions were matched in terms of general movement, head movement and eye movement of the animated torso. The lip movement was always in perfect synchrony with the auditory stimulation of the word.

The animations were presented using Presentation software (www.neurobehavioralsystems.com) via a projector that rear-projected the stimuli onto a screen which was viewed by the participants with the aid of a mirror mounted on the head coil. The distance to screen was about $59 \mathrm{~cm}$ and the width of projection was $32.5 \mathrm{~cm}$. Audio-information was presented via MRI compatible electrodynamic headphones integrated into earmuffs to reduce residual background scanner noise (Baumgartner et al., 2006). The sound level of stimuli was individually adjusted to achieve good audibility during data acquisition.

Functional MR images were acquired in a slow eventrelated design. In order to synchronize acquisition timing between scanner and stimulus-PC, the start of each trial was initiated by an external pulse from the scanner. At the beginning of the run a fixation cross was presented for $10 \mathrm{~s}$, followed by 120 trials. Each trial comprised an animation (stimulus), followed by a fixation cross of various durations (6-8 times TR). The order in which the animations were presented was randomized across conditions for each participant. Each participant saw 60 EMO (emotional facial expression congruently paired with 30 negative and 30 positive words) and 60 NEU (neutral facial expression paired with 30 negative and 30 positive words) videos. The functional run took $23 \mathrm{~min}$ and was followed by the acquisition of the structural data set.

Participants were asked to fixate the cross before and after each animation and to watch the videos in order to perform a subsequent memory test. In this memory test the stimuli were presented again randomly intermixed with an equal number of new videos of the same kind but animating different words. The participants had to decide for each stimulus whether it had been presented before or not. 


\section{fMRI acquisition and analysis}

Images were acquired on a 3T Siemens Magnetom Trio head scanner (Siemens Medical Systems, Erlangen, Germany) using a standard 8 channel head coil. Twenty-six oblique axial slices were acquired (in-plane resolution: $3.5 \times 3.5 \mathrm{~mm}$, slice thickness: $3.2 \mathrm{~mm}$, interslice distance $0.8 \mathrm{~mm}$ ) covering almost the entire cortical volume using an echo planar imaging sequence $(\mathrm{TR}=1600 \mathrm{~ms}$, field of view (FOV) $224 \mathrm{~mm}$, TE $=30 \mathrm{~ms}$, matrix size: $64 \times 64$, flip angle $75^{\circ}$ ). In total, 851 volumes were acquired of which the first 2 were discarded to allow for T1 saturation. Functional slices were aligned to a high-resolution T1-weighted anatomical scan acquired on the same scanner running a three-dimensional T1-fast-low-angle shot sequence lasting $9 \mathrm{~min}$ and $50 \mathrm{~s}$ (MPRAGE, 192 slices, slice thickness $1 \mathrm{~mm}$, TR $2500 \mathrm{~ms}$; TE $4.77 \mathrm{~ms}$; FA $7^{\circ}$; FOV $256 \mathrm{~mm}$; matrix $256 \times 256$ ).

Using BrainVoyager QX (Brain Innovation, Maastricht, The Netherlands) functional data were slice scan-time corrected, and corrected for motion in three dimensions. Subsequently, linear drifts were removed from the signal and data were high-pass filtered to remove slow frequency drifts up to 3 cycles per time course. Data were spatially smoothed with a Gaussian kernel of $6 \mathrm{~mm}$ (FWHM) and aligned to the last volume of the dataset, which was closest in time to the recording of the structural scan. The correction for movement during the run was done using a bi-cubic spline interpolation allowing the algorithm maximally 300 iterations for volume movement parameter estimation. Functional data were aligned to the high-resolution anatomical images, morphed to fit Talairach dimensions (Talairach and Tournoux, 1988) and combined into a 4dimensional $(x, y, z$, time) dataset for each run and each subject.

\section{Univariate statistical analysis}

Trials with emotional expression and without emotional expression were compared using random effects general linear model (RFX-GLM) analysis: in a first level, a standard GLM was used to estimate the beta values (summary statistics) for each subject and condition (level 1), which were then entered to the second level analysis as the dependent variable. At this level of analysis the main effect of animation was tested.

The correction for multiple comparisons was performed using cluster-size thresholding. The procedure started with setting a threshold (manually) for the map relative to the contrast of interest with a $p<0.005$ (uncorrected). Next, the intrinsic smoothness of the resulting map was evaluated automatically (Forman et al., 1995; Goebel et al., 2006). The final result was a minimum cluster size threshold set for the current map to achieve a corrected $p$ value of $<0.005$.

\section{Connectivity analysis}

To reveal the brain network underlying the perception of affective facial expression GCM, a vector autoregressive modeling technique, was used to define effective and/or functional connectivity (Goebel et al., 2003; Roebroeck et al., 2005). Briefly, the average blood oxygen leveldependent (BOLD) response collected across time from a volume of interest (VOI) make up a vector time series, $x i(t)$, where $t$ represents time and $i$ denotes the VOI. To identify and characterize effective connectivity in GCM, it is assumed that the time series $x(t)$ is a function of its own past $x(t-l, \ldots, t-p)$ and possibly of the past of another VOI or single voxel $y(t-l, \ldots, t-p)$. Therefore, it can be stated that if there is causality between $x$ and $y$, the present value of $x$ can be better predicted using the information of both time series $x(t)$ and $y(t)$ compared with solely using the information in time series $x(t)$. Furthermore, the number of time series that can be used to predict the current value $x$ can be more than two. This method, unlike some other methods for testing connectivity, does not require the a priori definition of a network including all brain areas to be tested. On the basis of Granger causality, the existence and direction of influence on and from the seeding region in respect to the rest of the brain can be investigated. In addition to directed causality the instantaneous influence (correlation) between $x(t)$ and $y(t)$ can be detected when values $x(t)$ improve predictions of synchronous values $y(t)$ (or vice versa, instantaneous correlation is symmetric), taking into account all other relevant sources of influence (at the very least the past of both $x$ and $y$ ). Note, therefore, that the instantaneous correlation reported here is subtly

Table 1. Univariate analysis emotional expression $(E M O)>$ neutral expression (NEU)

\begin{tabular}{|c|c|c|c|c|c|c|}
\hline Region of activation & Laterality & Coordinates & Voxels & BA & $\mathrm{t}$ Value & $p$ Value \\
\hline \multicolumn{7}{|l|}{ Main effect EMO > NEU } \\
\hline Amygdala & $\mathrm{L}$ & $-21-11-9$ & 516 & & 4.2028 & 0.0018 \\
\hline Amygdala & $\mathrm{R}$ & $18-12-10$ & 270 & & 3.9989 & 0.0021 \\
\hline Middle temporal gyrus & $\mathrm{L}$ & $-49-631$ & 1130 & 37 & 3.9290 & 0.0023 \\
\hline Middle temporal gyrus & $\mathrm{R}$ & $48-594$ & 1556 & 37 & 4.3237 & 0.0016 \\
\hline Fusiform gyrus & $\mathrm{L}$ & $-46-70-10$ & 1234 & 19 & 3.8575 & 0.0025 \\
\hline Fusiform gyrus & $\mathrm{R}$ & $44-66-12$ & 1588 & 19 & 4.1743 & 0.0018 \\
\hline Fusiform gyrus (anterior) & $\mathrm{L}$ & $-37-52-14$ & 517 & 19 & 3.7685 & 0.0027 \\
\hline Inferior occipital gyrus & $\mathrm{R}$ & $36-80-1$ & 1248 & 18 & 4.1439 & 0.0018 \\
\hline Middle occipital gyrus & $\mathrm{L}$ & $-35-775$ & 422 & 19 & 3.5800 & 0.0035 \\
\hline Middle occipital gyrus & $\mathrm{L}$ & $-40-627$ & 578 & 37 & 3.8498 & 0.0026 \\
\hline
\end{tabular}

These coordinates represent the center of gravity of the cluster in Tailarach space. The $t$-value is the average value of the cluster, and the $p$-value the average value for the voxels contained in the cluster. All contrasts have been cluster threshold corrected for multiple comparisons at a level of $p<0.005$. BA $=$ Brodmann area. 
A
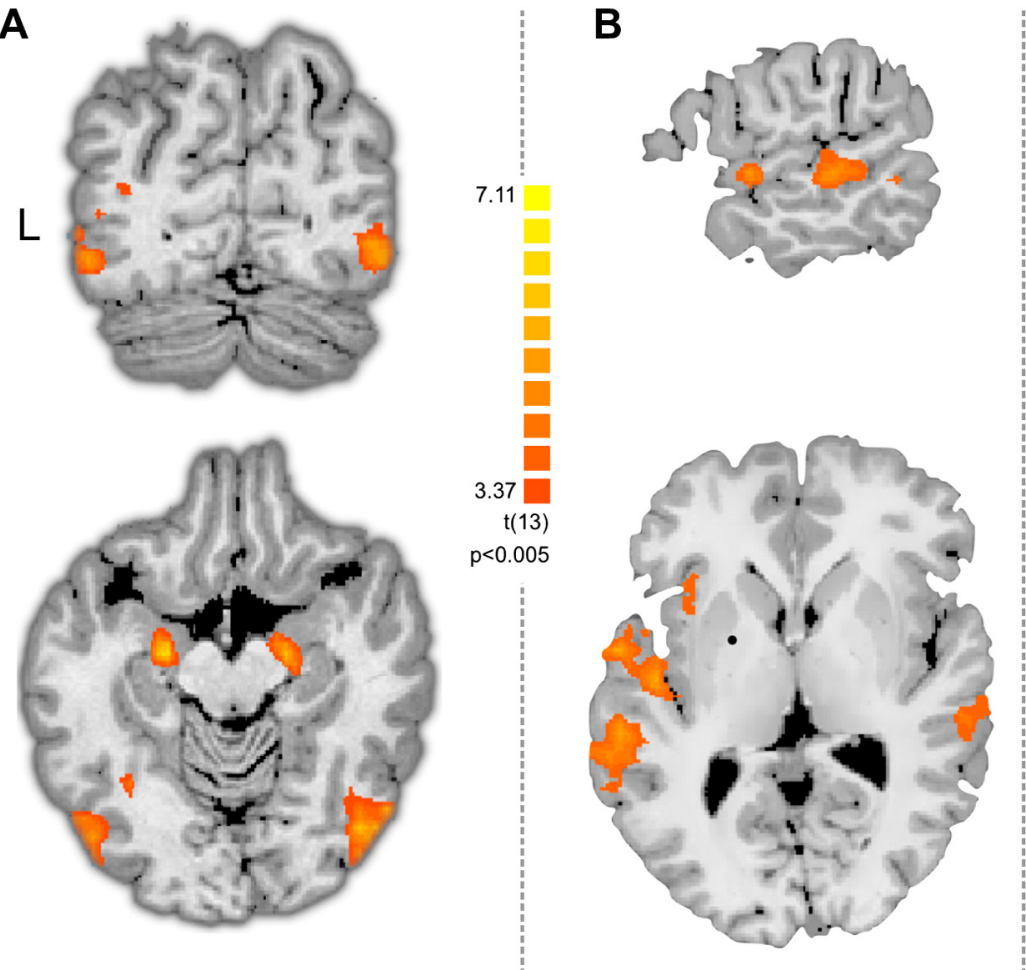

D
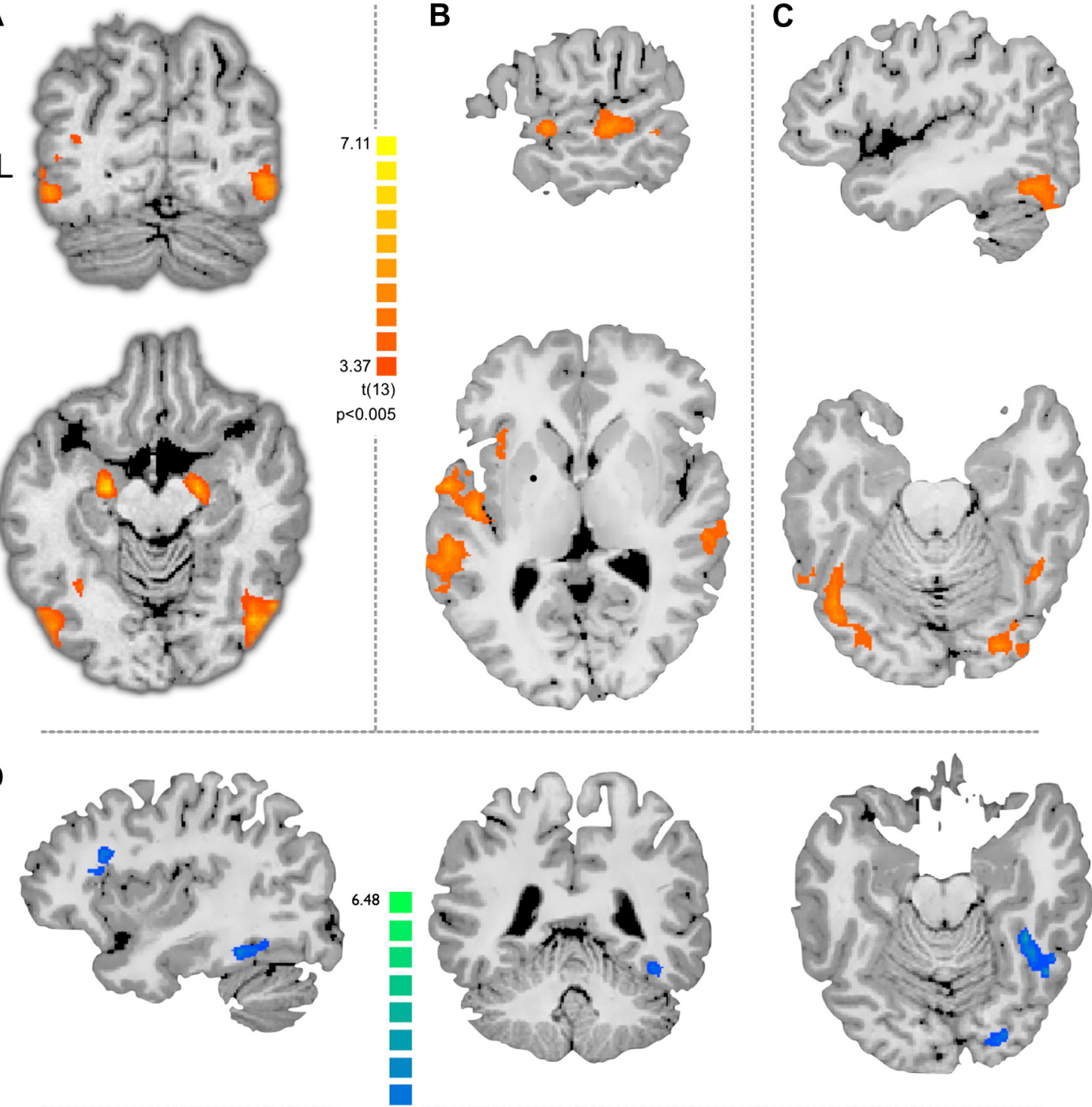

\section{E}
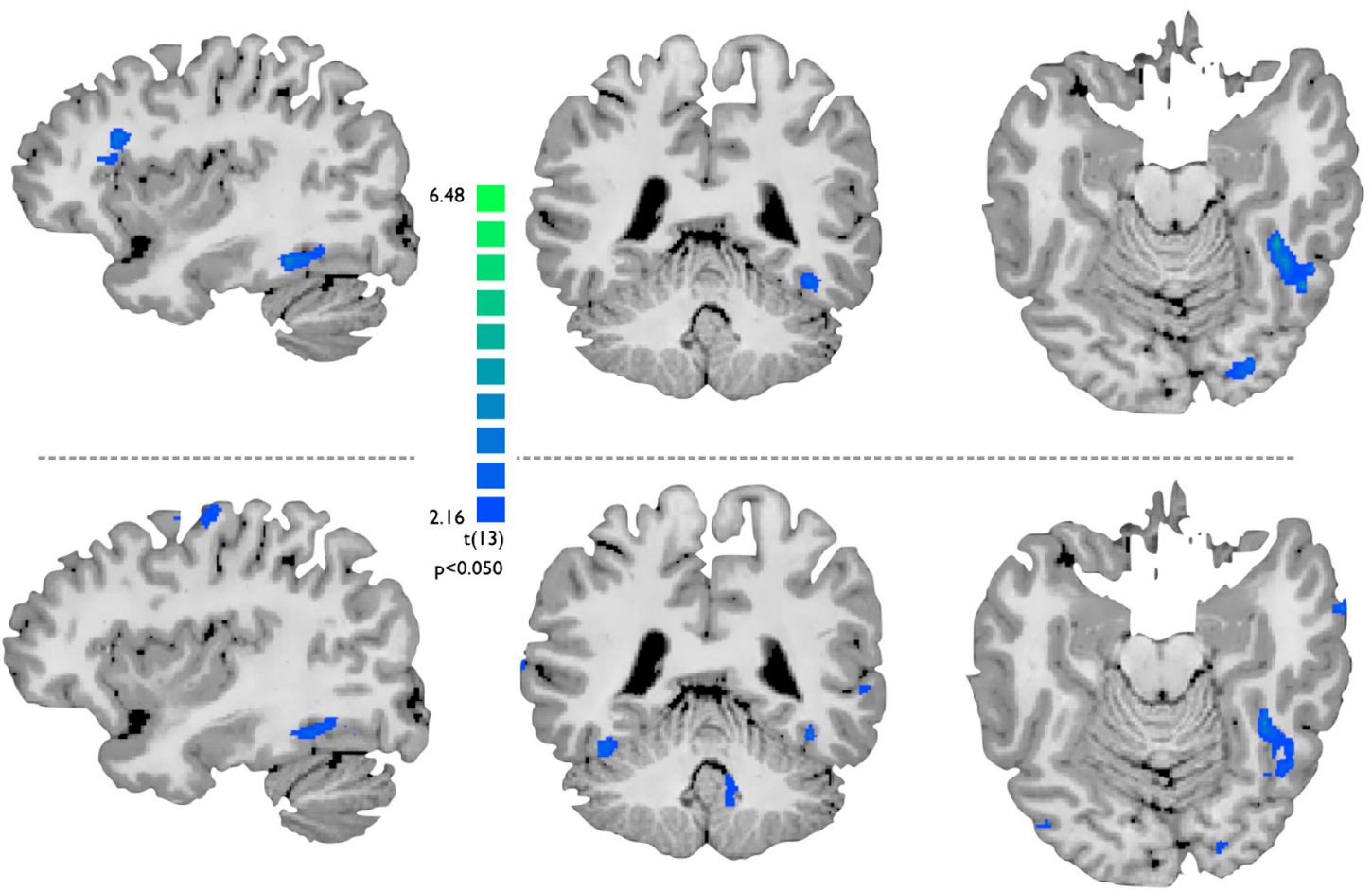

Fig. 1. (A) Univariate analysis. Contrast for affective emotional facial expression against a neutral facial expression giving activation of the amygdala, middle temporal gyrus and fusiform gyrus. $(\mathrm{B}, \mathrm{C}) t$-Test for instantaneous GCM between EMO and NEU for left and right amygdala seeds revealed connectivity differences in the fusiform gyrus, inferior occipital area and temporal pole. Only the left amygdala showed (bilateral) connectivity with the superior temporal gyrus, IFG and auditory cortex. (D, E) $t$-Test between the directed GCM results of EMO and NEU revealed a connectivity difference in the right fusiform gyrus for both left and right amygdala. The source of influence to both left and right amygdala is lateralized in the right fusiform gyrus/sulcus.

different from a standard correlation value in that the instantaneous correlation is conditioned on the past of the involved time-series. The advantage is that this way all linear statistical dependence between two time-series is divided into directional ( $x$ to $y$ and $y$ to $x$ ) and instantaneous correlation. 
Seeding regions were defined according to univariate analysis results of the contrast between EMO and NEU conditions. For all seeding regions, a region in the left hemisphere was defined as well as a region in the right hemisphere. The seed regions used were: amygdala, inferior occipital area, and superior temporal gyrus/MTG. For each subject and each region a GCM analysis was performed (FDR corr. $q<0.05$ ) and the resulting beta values were used as input for a random-effects (RFX)GCM over all subjects (FDR corr. $q<0.05$ ). Subsequently a paired $t$-test was performed between the RFX-GCM beta values for EMO and NEU to reveal the effect of emotional affective expression within the neural network.

\section{RESULTS}

\section{Memory test}

Participants showed equal memory performance for EMO (Hits minus false alarms $74.3 \%$, SD 8.9 ) and NEU $(72.8 \%$, SD 9.1) stimuli. This indicates that both classes of stimuli had been attended during the scanning session.

\section{Univariate statistical analysis}

The second level analysis, using the beta values of the first level analysis, revealed greater activation in bilateral amygdala, fusiform gyrus, MTG, and inferior occipital gyrus for emotional vs. neutral animations (Table 1, Fig. 1A). As in both conditions the words were spoken with an appropriate emotional prosody, this contrast could be also thought of as congruent (same emotional valence in the visual and auditory modality) vs. incongruent (visual modality: neutral; auditory modality: emotional). There were no brain areas which showed greater BOLD modulation for neutral animations at the chosen threshold (cluster threshold corrected for multiple comparisons at a level of $p<0.005$ ).

\section{Connectivity analysis}

The Instantaneous GCM for the right amygdala (Fig. 2) and left amydala (not shown) revealed a comparable network encompassing bilateral fusiform gyrus, inferior occipital areas, auditory cortex, superior temporal gyrus, parahippocampal gyrus, medial frontal gyrus, anterior cingulate, putamen and insula (Table 2, Fig. 2). The $t$ test for Instantaneous GCM between EMO and NEU for left and right amygdala seeds revealed connectivity differences in the respective neural networks. These differences were found in the fusiform gyrus, inferior occipital area and temporal pole. Only the left amygdala showed (bilateral) connectivity with the superior temporal gyrus, IFG and auditory cortex (Table 4, Fig. 1B, 1C).

The Directed GCM for the right amygdala (Fig. 2) and left amygdala (not shown) seeds revealed a network in which both right and left amygdala receive input from the right fusiform gyrus and from bilateral superior temporal gyrus, putamen, IFG, anterior cingulate gyrus, posterior cingulate gyrus, thalamus and anterior temporal pole. In addition, the right amygdala also receives input from the bilateral auditory cortex, cuneus, cerebellum and early visual areas. Both left and right amygdala show output to bilateral inferior occipital areas, parahippocampal gyrus and caudate (head). Only the left amygdala shows output into the left fusiform gyrus (Table 3).

A $t$-test between the Directed GCM results of EMO and NEU revealed a connectivity difference in the right fusiform gyrus for both left and right amygdala. In addition, there was a connectivity difference in the anterior part of bilateral fusiform gyrus and in the right
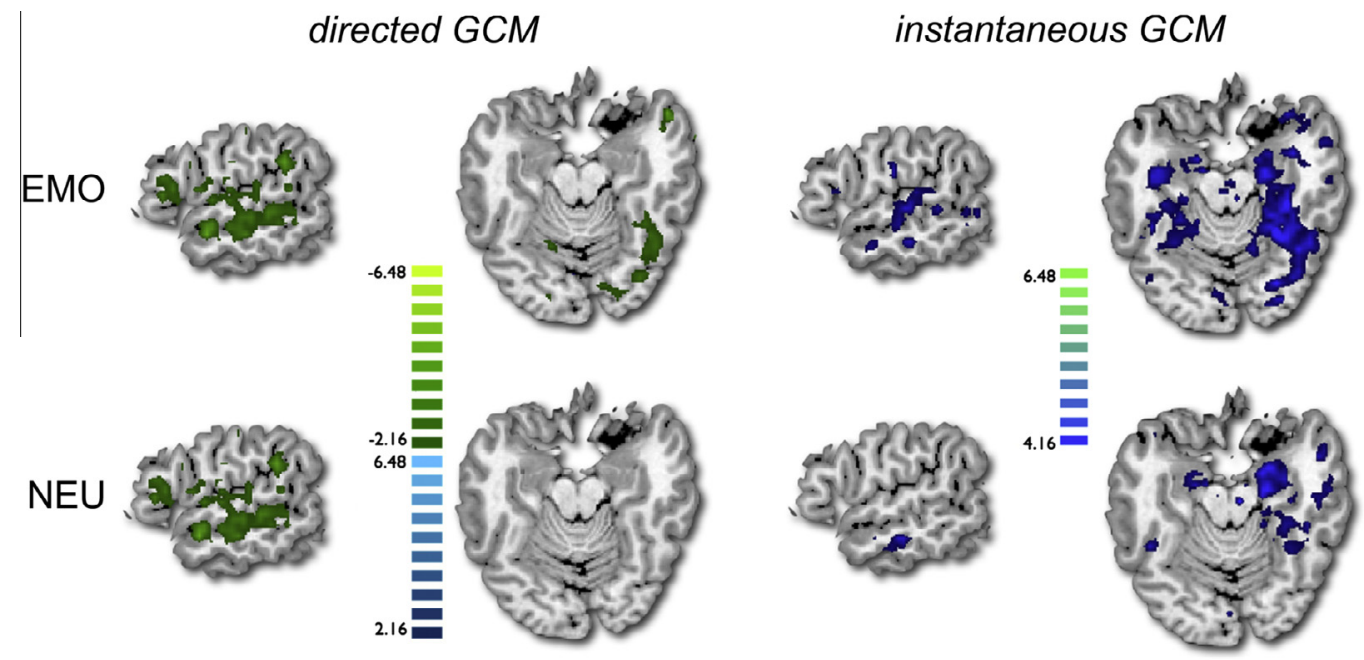

Fig. 2. The directed GCM results for the I right amygdala show connectivity with the right fusiform gyrus and superior/middle temporal gyrus. Positive $t$-values (blue) denote influence from the seeding region to the indicated cluster and vice versa, negative $t$-values (green) denote influence from the indicated cluster on the seeding region. The Instantaneous GCM for the right amygdala revealed a network encompassing bilateral fusiform gyrus, inferior occipital areas, auditory cortex, anterior temporal pole, medial frontal gyrus, cingulate gyrus and pons. (For interpretation of the references to color in this figure legend, the reader is referred to the web version of this article.) 
Table 2. Seed right amygdala (TAL $18-12-10)$. Brain areas revealed by instant GCM analysis for emotional (EMO) and neutral (NEU) conditions

\begin{tabular}{|c|c|c|c|c|c|}
\hline Region of activation & Laterality & Coordinates & BA & $t$ Value & $p$ Value \\
\hline \multicolumn{6}{|l|}{ Instant $R H$ amygdala EMO } \\
\hline Fusiform gyrus & $\mathrm{R}$ & $29-34-16$ & 20 & 4.756 & 0.0005 \\
\hline Fusiform gyrus & $\mathrm{R}$ & $33-51-16$ & 37 & 4.821 & 0.0004 \\
\hline Middle occipital gyrus & $\mathrm{R}$ & $47-52-6$ & 37 & 4.887 & 0.0004 \\
\hline Middle temporal gyrus & $\mathrm{R}$ & $59-17-12$ & 21 & 4.522 & 0.0006 \\
\hline Middle temporal gyrus & $\mathrm{R}$ & $532-16$ & 21 & 4.494 & 0.0006 \\
\hline Superior temporal gyrus & $\mathrm{R}$ & $57-151$ & 22 & 4.558 & 0.0006 \\
\hline Superior temporal gyrus & $\mathrm{R}$ & $54-209$ & 41 & 4.426 & 0.0007 \\
\hline Amygdala & $\mathrm{R}$ & $25-6-8$ & & 5.793 & 0.0002 \\
\hline Parahippocampal gyrus & $\mathrm{R}$ & $22-28-3$ & 27 & 4.691 & 0.0005 \\
\hline Parahippocampal gyrus & $\mathrm{R}$ & $8-421$ & 30 & 4.608 & 0.0005 \\
\hline Parahippocampal gyrus & $\mathrm{R}$ & $21-29-7$ & 28 & 4.706 & 0.0005 \\
\hline Medial frontal gyrus & $\mathrm{R}$ & 111442 & 32 & 4.589 & 0.0006 \\
\hline Fusiform gyrus & $\mathrm{L}$ & $-36-38-16$ & 20 & 4.497 & 0.0006 \\
\hline Fusiform gyrus & $\mathrm{L}$ & $-40-57-11$ & 37 & 4.988 & 0.0004 \\
\hline Middle temporal gyrus & $\mathrm{L}$ & $-48-584$ & 37 & 4.809 & 0.0004 \\
\hline Superior temporal gyrus & $\mathrm{L}$ & $-46-6118$ & 39 & 4.635 & 0.0005 \\
\hline Superior temporal gyrus & $\mathrm{L}$ & $-55-248$ & 41 & 4.519 & 0.0006 \\
\hline Superior temporal gyrus & $\mathrm{L}$ & $-46-102$ & 22 & 4.803 & 0.0005 \\
\hline Middle temporal gyrus & $\mathrm{L}$ & $-53-28-2$ & 21 & 4.392 & 0.0007 \\
\hline Middle temporal gyrus & $\mathrm{L}$ & $-56-8-8$ & 21 & 4.804 & 0.0005 \\
\hline Amygdala & $\mathrm{L}$ & $-23-10-9$ & & 4.927 & 0.0004 \\
\hline Lingual gyrus & $\mathrm{L}$ & $-12-521$ & 19 & 4.675 & 0.0005 \\
\hline Thalamus & $\mathrm{L}$ & $-12-310$ & & 4.821 & 0.0005 \\
\hline Anterior cingulate & $\mathrm{L}$ & -1461 & 32 & 4.710 & 0.0005 \\
\hline Cingulate gyrus & $\mathrm{L}$ & -91640 & 32 & 4.635 & 0.0006 \\
\hline \multicolumn{6}{|l|}{ Instant $R H$ amygdala NEU } \\
\hline Fusiform gyrus & $\mathrm{R}$ & $33-45-16$ & 37 & 4.615 & 0.0006 \\
\hline Fusiform gyrus & $\mathrm{R}$ & $31-36-16$ & 20 & 4.569 & 0.0006 \\
\hline Middle temporal gyrus & $\mathrm{R}$ & $51-15-17$ & 21 & 4.541 & 0.0006 \\
\hline Superior temporal gyrus & $\mathrm{R}$ & $4410-9$ & 38 & 4.554 & 0.0006 \\
\hline Parahippocampal gyrus & $\mathrm{R}$ & $20-13-14$ & 28 & 6.495 & 0.0001 \\
\hline Parahippocampal gyrus & $\mathrm{R}$ & $6-340$ & 30 & 4.715 & 0.0005 \\
\hline Fusiform gyrus & $\mathrm{L}$ & $-40-44-15$ & 37 & 4.499 & 0.0006 \\
\hline Middle temporal gyrus & $\mathrm{L}$ & $-51-542$ & 37 & 4.526 & 0.0006 \\
\hline Amygdala & $\mathrm{L}$ & $-20-10-10$ & & 4.753 & 0.0005 \\
\hline Thalamus & $\mathrm{L}$ & $-12-313$ & & 4.669 & 0.0005 \\
\hline Anterior cingulate & $\mathrm{L}$ & $-147-3$ & 32 & 4.564 & 0.0006 \\
\hline Parahippocampal gyrus & $\mathrm{L}$ & $-4-440$ & 30 & 4.793 & 0.0005 \\
\hline Middle frontal gyrus & $\mathrm{L}$ & -211956 & 6 & 4.599 & 0.0005 \\
\hline Superior temporal gyrus & $\mathrm{L}$ & $-47-115$ & 22 & 4.373 & 0.0007 \\
\hline
\end{tabular}

Clusters were found in the volume data. The Talairach coordinates represent the center of gravity of the cluster. BA stands for the Brodmann area. The $t$-value is the average value for the cluster, and the $p$-value the average value of the voxels contained in the cluster.

hemispheric STS/MTG for the right amygdala seed (Table 2, Fig. 1D, E).

\section{DISCUSSION}

We used fMRI in combination with functional connectivity analysis to investigate the integration of emotional facial expression and emotional auditory input. The univariate analysis revealed bilateral activation in the inferior occipital areas, fusiform gyrus and amygdala for emotional vs. neutral stimuli with is in line with earlier studies (Haxby et al., 2000; Adolphs, 2002a,b; Ethofer et al., 2006a). Please note, that we contrasted emotional facial information (positive or negative) paired with emotionally congruent (positive or negative) prosody and emotionally neutral faces paired with incongruent emotional (positive or negative) prosody, rather than focusing on differences between positively and negatively valence stimuli. While there is evidence for specialization for certain brain areas for positive or negative emotional information (Wager et al., 2003), the emphasis of the current study was on the congruency/ incongruency of facial and prosodic information.

Importantly, the fusiform gyrus was more activated for EMO than NEU implicating this structure in the processing of affective facial expressions again compatible with earlier studies (Adolphs, 2002b; de Gelder et al., 2003; Ganel et al., 2005; Vuilleumier, 2005; Ishai, 2008). In addition, the MTG next to the STS showed more activation for EMO compared to NEU stimuli as well. This echoes earlier observations suggesting a role of this region for the integration of 
Table 3. Seed right amygdala (TAL 18-12-10). Brain areas revealed by directed GCM analysis for emotional (EMO) and (NEU) conditions

\begin{tabular}{|c|c|c|c|c|c|}
\hline Region of activation & Laterality & Coordinates & $\mathrm{BA}$ & $t$ Value & $p$ Value \\
\hline \multicolumn{6}{|l|}{ Directed $R H$ amygdala EMO } \\
\hline Lingual gyrus & $\mathrm{R}$ & $16-81-8$ & 18 & -2.516 & 0.028 \\
\hline Cingulate gyrus & $\mathrm{R}$ & $7-2532$ & 23 & -2.547 & 0.027 \\
\hline Cingulate gyrus & $\mathrm{R}$ & 122630 & 32 & -2.503 & 0.029 \\
\hline Middle frontal gyrus & $\mathrm{R}$ & 473423 & 46 & -2.538 & 0.027 \\
\hline Inferior frontal gyrus & $\mathrm{R}$ & 43930 & 9 & -2.639 & 0.025 \\
\hline Middle temporal gyrus & $\mathrm{R}$ & $58-21-3$ & 21 & -2.642 & 0.023 \\
\hline Superior temporal gyrus & $\mathrm{R}$ & $43-4415$ & 13 & -2.542 & 0.028 \\
\hline Fusiform gyrus & $\mathrm{R}$ & $38-59-11$ & 37 & -2.483 & 0.298 \\
\hline Putamen & $\mathrm{R}$ & $30-167$ & & -2.425 & 0.032 \\
\hline Thalamus & $\mathrm{R}$ & $11-177$ & & -2.522 & 0.028 \\
\hline Superior temporal gyrus & $\mathrm{R}$ & $52-1311$ & 22 & -2.489 & 0.030 \\
\hline Inferior parietal lobule & $\mathrm{R}$ & $53-3729$ & 40 & -2.614 & 0.025 \\
\hline Parahippocampal gyrus & $\mathrm{R}$ & $5-380$ & 30 & 2.581 & 0.026 \\
\hline Caudate head & $\mathrm{R}$ & 2111 & & 2.657 & 0.024 \\
\hline Parahippocampal gyrus & $\mathrm{L}$ & $-10-412$ & 30 & 2.457 & 0.031 \\
\hline Superior temporal gyrus & $\mathrm{L}$ & $-45-2912$ & 41 & -2.581 & 0.026 \\
\hline Superior temporal gyrus & $L$ & $-44-5117$ & 21 & -2.397 & 0.034 \\
\hline Putamen & $\mathrm{L}$ & -2378 & & -2.493 & 0.029 \\
\hline Anterior cingulate & $\mathrm{L}$ & -9445 & 32 & -2.556 & 0.027 \\
\hline Posterior cingulate & $\mathrm{L}$ & $-8-6516$ & 31 & -2.671 & 0.023 \\
\hline Medial frontal gyrus & $\mathrm{L}$ & -94624 & 9 & -2.443 & 0.032 \\
\hline Precuneus & $\mathrm{L}$ & $-20-7027$ & 31 & -2.561 & 0.027 \\
\hline Cingulate gyrus & $\mathrm{L}$ & $-4-2734$ & 31 & -2.628 & 0.024 \\
\hline Superior temporal gyrus & $\mathrm{L}$ & $-49-4414$ & 22 & -2.454 & 0.031 \\
\hline Inferior frontal gyrus & $\mathrm{L}$ & -54527 & 9 & -2.674 & 0.023 \\
\hline \multicolumn{6}{|l|}{ Directed $R H$ amygdala NEU } \\
\hline Superior temporal gyrus & $\mathrm{R}$ & $47-319$ & 41 & -2.801 & 0.018 \\
\hline Middle temporal gyrus & $\mathrm{R}$ & $49-534$ & 37 & -2.160 & 0.025 \\
\hline Superior frontal gyrus & $\mathrm{R}$ & 434030 & 9 & -2.574 & 0.026 \\
\hline Inferior parietal lobule & $\mathrm{R}$ & $57-1923$ & 40 & -2.464 & 0.030 \\
\hline Posterior cingulate & $\mathrm{R}$ & $10-6711$ & 30 & -2.341 & 0.036 \\
\hline Cingulate gyrus & $\mathrm{R}$ & $5-6026$ & 31 & -2.357 & 0.035 \\
\hline Caudate head & $\mathrm{R}$ & $8-172$ & & -2.469 & 0.031 \\
\hline Putamen & $\mathrm{L}$ & $-24-1410$ & & -2.529 & 0.028 \\
\hline Transverse temporal gyrus & $\mathrm{L}$ & $-50-2511$ & 41 & -2.601 & 0.026 \\
\hline Lingual gyrus & $\mathrm{L}$ & $-2-73-4$ & 18 & -2.401 & 0.033 \\
\hline Precuneus & $\mathrm{L}$ & $-9-6218$ & 31 & -2.471 & 0.030 \\
\hline Superior temporal gyrus & $\mathrm{L}$ & $-52-210$ & 21 & -2.626 & 0.024 \\
\hline Postcentral gyrus & $\mathrm{L}$ & $-55-2617$ & 40 & -2.503 & 0.030 \\
\hline Precentral gyrus & $\mathrm{L}$ & -351138 & 9 & -2.472 & 0.031 \\
\hline
\end{tabular}

Clusters were found in the volume data. The Talairach coordinates represent the center of gravity of the cluster. BA stands for the Brodmann area. The $t$-value is the average value for the cluster, and the $p$-value the average value of the voxels contained in the cluster. Positive $t$-values denote influence from the seeding region to the indicated cluster and vice versa, negative $t$-values denote influence from the indicated cluster on the seeding region.

emotional information from face and voice (Pourtois et al., 2005; Ethofer et al., 2006a,b; Kreifelts et al., 2007, 2009).

Directed Granger causality was used to shed some light on the direction of information flow between the amygdala and the fusiform gyrus. The GCM technique is specifically aimed at extracting the direction of information flow in the brain without prior assumption on that direction (directed GCM), or showing that no such direction can be found (instantaneous GCM). Directed GCM showed a difference in connectivity direction between the right and left hemisphere, from the amygdala to the fusiform gyrus. Bilateral amygdala receives input mainly from the right hemisphere fusiform gyrus and output is directed mainly to the left hemisphere. This difference might explain why some studies report bilateral activation of the fusiform gyrus with possible right hemispheric dominance (Allison et al., 1994; Pourtois et al., 2005; Kanwisher and Yovel, 2006; Engell and Haxby, 2007) while other studies report mainly or only activation in the right hemisphere (Rossion et al., 2003; Ganel et al., 2005; Vuilleumier and Pourtois, 2007). This difference in activity between both hemispheres might be dependent on the processing route via intermediate task-related areas.

The results are summarized in Fig. 3 with brain areas revealed by our analysis displayed as boxes and information flow as arrows. The brain network is organized into a model taking previous models as a departure point. According to the classical model by(Bruce and Young, 1986) facial expression and facial identity are processed by separate routes. This separation is also a feature of a model proposed by 
Table 4. Instantaneous GCM and directed GCM analysis, emotional expression (EMO) > neutral expression (NEU)

\begin{tabular}{|c|c|c|c|c|c|}
\hline Region of activation & Laterality & Coordinates & BA & t Value & $p$ Value \\
\hline \multicolumn{6}{|c|}{ Instantaneous left amygdala EMO > NEU } \\
\hline Superior temporal gyrus & $\mathrm{R}$ & $58-122$ & 22 & 2.581 & 0.0269 \\
\hline Middle temporal gyrus & $\mathrm{R}$ & $54-29-4$ & 21 & 2.383 & 0.0343 \\
\hline Lingual gyrus & $\mathrm{R}$ & $13-90-13$ & 18 & 2.163 & 0.0306 \\
\hline Lingual gyrus & $\mathrm{L}$ & $-9-93-9$ & 17 & 2.161 & 0.0356 \\
\hline Superior temporal gyrus & $\mathrm{L}$ & $-483-1$ & 22 & 2.160 & 0.0233 \\
\hline Superior temporal gyrus & $\mathrm{L}$ & $-48-11-1$ & 22 & 2.734 & 0.0218 \\
\hline Middle temporal gyrus & $\mathrm{L}$ & $-55-393$ & 22 & 2.160 & 0.0222 \\
\hline \multicolumn{6}{|c|}{ Instantaneous right amygdala EMO > NEU } \\
\hline Fusiform gyrus & $\mathrm{L}$ & $-41-59-20$ & 37 & 2.669 & 0.0237 \\
\hline Fusiform gyrus & $\mathrm{L}$ & $-40-52-20$ & 37 & 2.575 & 0.0274 \\
\hline Lateral occipital gyrus & $\mathrm{L}$ & $-28-85-14$ & 18 & 2.429 & 0.0323 \\
\hline Lingual gyrus & $\mathrm{L}$ & $-12-83-14$ & 18 & 2.465 & 0.0306 \\
\hline Fusiform gyrus & $\mathrm{R}$ & $26-84-16$ & 18 & 2.600 & 0.0267 \\
\hline Inferior occipital gyrus & $\mathrm{R}$ & $38-82-17$ & 18 & 2.482 & 0.0305 \\
\hline Fusiform gyrus & $\mathrm{R}$ & $41-50-19$ & 37 & 2.536 & 0.0280 \\
\hline \multicolumn{6}{|c|}{ Directed left amygdala EMO > NEU } \\
\hline Uncus & $\mathrm{L}$ & $-296-23$ & 28 & 2.560 & 0.0272 \\
\hline Fusiform gyrus & $\mathrm{R}$ & $22-84-15$ & 37 & -2.464 & 0.0308 \\
\hline Fusiform gyrus & $\mathrm{R}$ & $38-49-15$ & 21 & -2.704 & 0.0233 \\
\hline Middle temporal gyrus & $\mathrm{R}$ & $61-28-6$ & 21 & -2.489 & 0.0302 \\
\hline Middle temporal gyrus & $\mathrm{R}$ & $63-9-6$ & 18 & -2.472 & 0.0314 \\
\hline \multicolumn{6}{|c|}{ Directed right amygdala $E M O>N E U$} \\
\hline Inferior occipital gyrus & $\mathrm{L}$ & $-43-81-12$ & 19 & -2.591 & 0.0271 \\
\hline Fusiform gyrus & $\mathrm{L}$ & $-33-74-10$ & 22 & -2.420 & 0.0329 \\
\hline Middle temporal gyrus & $\mathrm{L}$ & $-59-384$ & 22 & -2.307 & 0.0397 \\
\hline Superior temporal gyrus & $\mathrm{L}$ & $-4811-4$ & 37 & -2.311 & 0.0387 \\
\hline Fusiform gyrus & $\mathrm{R}$ & $43-59-17$ & 37 & -2.504 & 0.0291 \\
\hline Fusiform gyrus & $\mathrm{R}$ & $21-80-13$ & 19 & -2.355 & 0.0362 \\
\hline Middle temporal gyrus & $\mathrm{R}$ & $56-34-3$ & & -2.421 & 0.0323 \\
\hline Middle temporal gyrus & $\mathrm{R}$ & $62-6-6$ & 21 & -2.642 & 0.0250 \\
\hline
\end{tabular}

These coordinates represent the center of gravity of the cluster in Tailarach space. The $t$-value is the average value of the cluster, and the $p$-value the average value for the voxels contained in the cluster. All contrasts have been cluster threshold corrected for multiple comparisons at a level of $p<0.005$. BA $=$ Brodmann area.

Haxby et al. (2000) who, on the basis of neuroimaging results, posit that the inferior occipital gyri are involved in early perception of facial features. From there, one pathway goes to the STS, which is thought to process changeable aspects of faces such as direction of eye gaze, view angle, emotional expression, and lip movement. Another pathway goes to the lateral fusiform gyrus, which is responsible for processing identity. Our extension of the model also integrates the processing of other information such as non-verbal emotional information. We propose that the dynamic extraction of information from faces and its integration with corresponding auditory information is achieved by the interplay of several different systems: (A) an Input system features components responsible for visual analysis, directing visual attention and auditory analysis (Calder and Young, 2005; Vuilleumier and Pourtois, 2007), (B) a Limbic system hosts components responsible for the extraction of emotional information from the input signal, which is rapidly transmitted to both cortical and sub-cortical areas (Adolphs, 2002b). The amygdala has been implicated as a crossmodal integration site for emotional information (Dolan et al., 2001). In the current instantiation, the model does not distinguish between processing of positive or negative emotional information. Given the amygdala's preference for negative information, further studies should test the model with regard to the valence of the stimuli. (C) An Integration system is hypothesized to integrate the information from the different systems (Campanella and Belin, 2007; Ethofer et al., 2006b). The STS is the main component of the integration system. Previous studies (e.g., Calvert et al., 2000; Szycik et al., 2008 have used the principle of superadditivity to demonstrate the role of the STS as an integration site. This principle has been criticized (Hocking and Price, 2008) but other findings, most notably the differences observed for congruent and incongruent stimuli (e.g., Szycik et al., 2009) suggest that one of the manifold functions (Hein and Knight, 2008) of the STS is crossmodal integration. (D) Finally, a context system is responsible for further task-related processing (Adolphs, 2002b). The functions of the systems are well documented in the neuroimaging literature and its connectivity pattern, empirically identified in the current experiment, dovetails nicely with other connectivity studies (Ethofer et al., 2006a; Fairhall and Ishai, 2007).

To summarize, Granger causal modeling allowed us to identify a network of brain areas involved in the integration of emotional facial and auditory information 


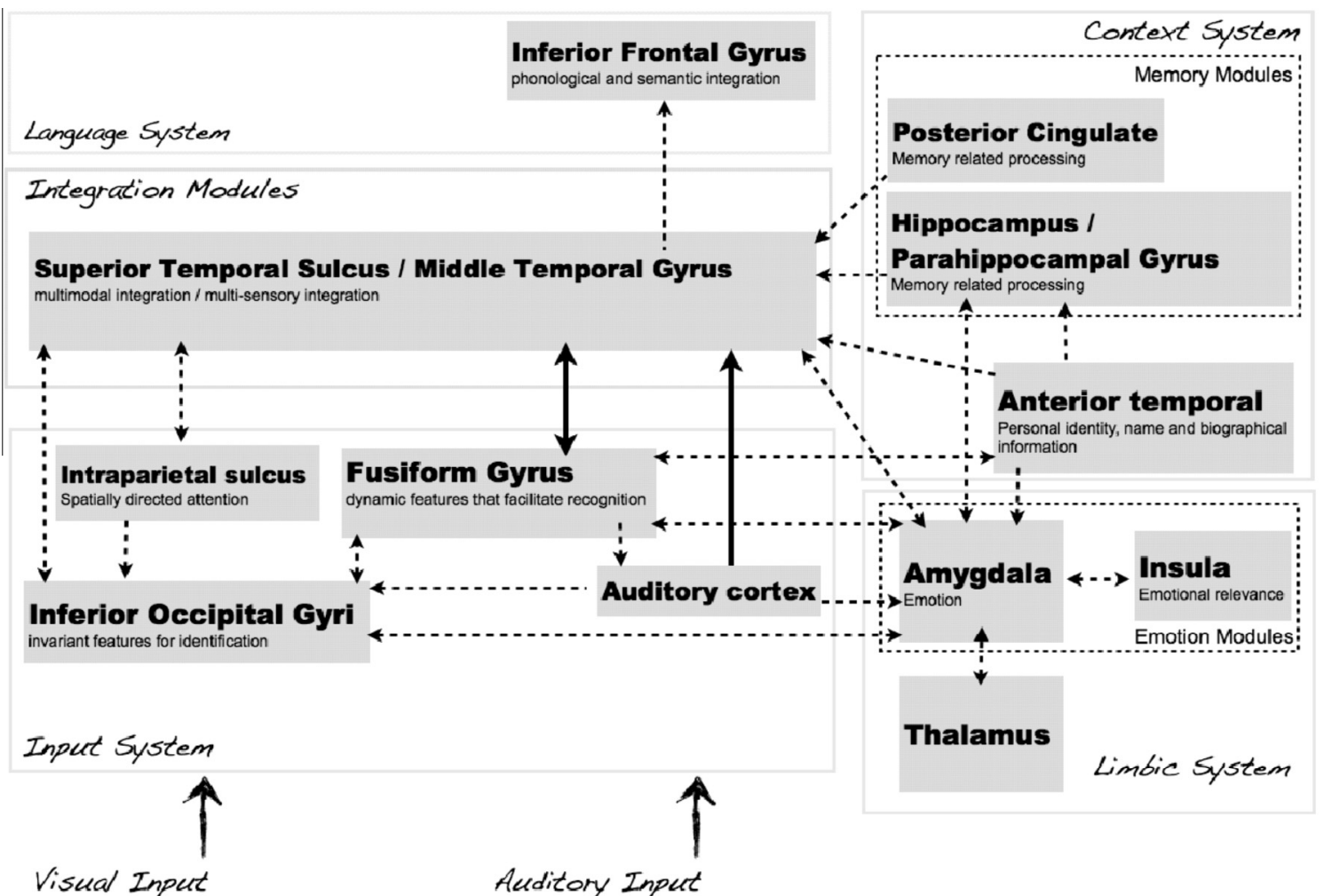

Fig. 3. Summary of the imaging results. Identified brain areas are grouped into several different systems with the information flow between areas denoted by arrows. For explanation, see main text.

and to delineate the information flow between these areas.

Acknowledgments-TFM is supported by the DFG and the $B M B F$. This particular project was carried out as part of the SFB TR 31, project A7. We thank the company Takomat, Cologne, Germany, for the production of the video stimuli.

\section{APPENDIX A. SUPPLEMENTARY DATA}

Supplementary data associated with this article can be found, in the online version, at http://dx.doi.org/10.1016/ j.neuroscience.2013.10.047.

\section{REFERENCES}

Adolphs R (2002a) Recognizing emotion from facial expressions: psychological and neurological mechanisms. Behav Cogn Neurosci Rev 1:21-62.

Adolphs R (2002b) Neural systems for recognizing emotion. Curr Opin Neurobiol 12:169-177.

Adolphs R, Damasio H, Tranel D (2002) Neural systems for recognizing emotional prosody. Emotion 2:23-51.

Allison T, Ginter H, McCarthy G, Nobre AC, Puce A, Luby M, Spencer DD (1994) Face recognition in human extrastriate cortex. J Neurophysiol 71:821-825.

Barraclough NE, Xiao D, Baker Cl, Oram MW, Perrett DI (2005) Integration of visual and auditory information by superior temporal sulcus neurons responsive to the sight of actions. J Cogn Neurosci 17:377-391.

Baumgartner T, Lutz K, Schmidt CF, Jancke L (2006) The emotional power of music: how music enhances the feeling of affective pictures. Brain Res 1075:151-164.
Belin P, Zatorre RJ, Ahad P (2002) Human temporal-lobe response to vocal sounds. Cogn Brain Res 13:17-26.

Bestelmeyer PE, Latinus M, Bruckert L, Rouger J, Crabbe F, Belin P (2012) Implicitly perceived vocal attractiveness modulates prefrontal cortex activity. Cereb Cortex 22:1263-1270.

Blair RJR, Morris JS, Frith CD, Perrett DI, Dolan RJ (1999) Dissociable neural responses to facial expressions of sadness and anger. Brain 122:883-893.

Blank H, Anwander A, von Kriegstein K (2011) Direct structural connections between voice- and face-recognition areas. J Neurosci 31:12906-12915.

Breiter HC, Etcoff NL, Whalen PJ, Kennedy WA, Rauch SL, Buckner RL, Strauss MM, Hyman SE, Rosen BR (1996) Response and habituation of the human amygdala during visual processing of facial expression. Neuron 17:875-887.

Bressler SL, Tang W, Sylvester CM, Shulman GL, Corbetta M (2008) Top-down control of human visual cortex by frontal and parietal cortex in anticipatory visual spatial attention. J Neurosci 28:10056-10061.

Bruce V, Young AW (1986) Understanding face recognition. Brit J Psychol 77:305-327.

Buchanan TW, Lutz K, Mirzazade S, Specht K, Shah NJ, Zilles K, Jäncke L (2000) Recognition of emotional prosody and verbal components of spoken language: an fMRI study. Cogn Brain Res 9:227-238.

Calder AJ, Young AW (2005) Understanding the recognition of facial identity and facial expression. Nat Rev Neurosci 6:641-651.

Calvert GA, Campbell R (2003) Reading speech from still and moving faces: the neural substrates of visible speech. J Cogn Neurosci 15:57-70.

Calvert GA, Campbell R, Brammer MJ (2000) Evidence from functional magnetic resonance imaging of crossmodal binding in the human heteromodal cortex. Curr Biol 10:649-657.

Campanella S, Belin P (2007) Integrating face and voice in person perception. Trends Cogn Sci 11:535-543. 
Collignon O, Girard S, Gosselin F, Roy S, Saint-Amour D, Lassonde M, Lepore F (2008) Audio-visual integration of emotion expression. Brain Res 1242:126-135.

Critchley HD, Daly E, Phillips M, Brammer M, Bullmore E, Williams S, van Amelsvoort T, Robertson D, David A, Murphy D (2000) Explicit and implicit neural mechanisms for processing of social information from facial expressions: a functional magnetic imaging study. Hum Brain Mapp 9:93-105.

de Gelder B, Vroomen J (2000) The perception of emotions by ear and by eye. Cognition \& Emotion 14:289-311.

de Gelder B, Bocker KB, Tuomainen J, Hensen M, Vroomen J (1999) The combined perception of emotion from voice and face: early interaction revealed by human electric brain responses. Neurosci Lett 260:133-136.

de Gelder B, Pourtois G, Weisskrantz L (2002) Fear recognition in the voice is modulated by unconsciously recognized facial expressions but not by unconsciously recognized affective pictures. Proc Natl Acad Sci USA 99:4121-4126.

de Gelder B, Frissen I, Barton J, Hadjikhani N (2003) A modulatory role for facial expressions in prosopagnosia. Proc Natl Acad Sci USA 100:13105-13110.

Dolan RJ, Morris JS, de Gelder B (2001) Crossmodal binding of fear in voice and face. Proc Natl Acad Sci USA 98:10006-10010.

Ekman P (1994) Strong evidence for universals in facial expressions: a reply to Russell_s mistaken critique. Psychol Bull 115:268-287.

Engell AD, Haxby JV (2007) Facial expression and gaze-direction in human superior temporal sulcus. Neuropsychologia 45:3234-3241.

Ethofer T, Anders S, Erb M, Droll C, Royen L, Saur R, Reiterer S, Grodd W, Wildgruber D (2006a) Impact of voice on emotional judgment of faces: an event-related fMRI study. Hum Brain Mapp 27:707-714.

Ethofer T, Pourtois G, Wildgruber D (2006b) Investigating audiovisual integration of emotional signals in the human brain. Prog Brain Res 156:345-360.

Ethofer T, Van De Ville D, Scherer K, Vuilleumier P (2009) Decoding of emotional information in voice-sensitive cortices. Curr Biol 19:1028-1033.

Fairhall SL, Ishai A (2007) Effective connectivity within the distributed cortical network for face perception. Cereb Cortex 17:2400-2406.

Forman SD, Cohen JD, Fitzgerald M, Eddy WF, Mintun MA, Noll DC (1995) Improved assessment of significant activation in functional magnetic resonance imaging (fMRI): use of a cluster-size threshold. Magn Reson Med 33:636-647.

Formisano E, Linden DE, Di Salle F, Trojano L, Esposito F, Sack AT, Grossi D, Zanella FE, Goebel R (2002) Tracking the mind's image in the brain I: timeresolved fMRI during visuospatial mental imagery. Neuron 35:185-194.

Ganel T, Valyear KF, Goshen-Gottstein Y, Goodale MA (2005) The involvement of the "fusiform face area" in processing facial expression. Neuropsychologia 43:1645-1654.

Gelder BD, Teunisse JP, Benson PJ (1997) Categorical perception of facial expressions: categories and their internal structure. Cognition \& Emotion 11:1-23.

Goebel R, Roebroeck A, Kim DS, Formisano E (2003) Investigating directed cortical interactions in time-resolved fMRI data using vector autoregressive modeling and Granger causality mapping. Magn Reson Imaging 21:1251-1261.

Goebel R, Esposito F, Formisano E (2006) Analysis of functional image analysis contest (FIAC) data with brainvoyager $\mathrm{QX}$ : from single-subject to cortically aligned group general linear model analysis and self-organizing group independent component analysis. Hum Brain Mapp 27:392-401.

Haxby JV, Hoffman EA, Gobbini MI (2000) The distributed human neural system for face perception. Trends Cogn Sci 4:223-233.

Hein G, Knight RT (2008) Superior temporal sulcus - it's my area: or is it? J Cogn Neurosci 20:2125-2136.

Hocking J, Price CJ (2008) The role of the posterior superior temporal sulcus in audiovisual processing. Cereb Cortex 18:2439-2449.
Ishai A (2008) Let's face it: it's a cortical network. Neuroimage 40:415-419.

Kanwisher N, Yovel G (2006) The fusiform face area: a cortical region specialized for the perception of faces. Philos Trans R Soc Lond B Biol Sci 361:2109-2128.

Klasen M, Kenworthy CA, Mathiak KA, Kircher TT, Mathiak K (2011) Supramodal representation of emotions. J Neurosci 31:13635-13643.

Kreifelts B, Ethofer T, Grodd W, Erb M, Wildgruber D (2007) Audiovisual integration of emotional signals in voice and face: an event-related fMRI study. Neuroimage 37:1445-1456.

Kreifelts B, Ethofer T, Shiozawa T, Grodd W, Wildgruber D (2009) Cerebral representation of non-verbal emotional perception: fMRI reveals audiovisual integration area between voice- and facesensitive regions in the superior temporal sulcus. Neuropsychologia 47:3059-3066.

McGurk H, MacDonald J (1976) Hearing lips and seeing voices. Nature 264:746-748.

Morris JS, Frith CD, Perrett DI, Rowland D, Young AW, Calder AJ, Dolan RJ (1996) A differential neural response in the human amygdala to fearful and happy facial expressions. Nature 383:812-815.

Morris JS, Scott SK, Dolan RJ (1999) Saying it with feeling: neural responses to emotional vocalizations. Neuropsychologia 37:1155-1163.

Noesselt T, Driver J, Heinze HJ, Dolan R (2005) Asymmetrical activation in the human brain during processing of fearful faces. Curr Biol 15:424-429.

Phillips ML, Young AW, Scott SK, Calder AJ, Andrew C, Giampietro V, Williams SCR, Bullmore ET, Brammer M, Gray JA (1998) Neural responses to facial and vocal expressions of fear and disgust. Proc R Soc London Ser B 265:1809-1817.

Pourtois G, de Gelder B, Vroomen J, Rossion B, Crommelinck M (2000) The time-course of intermodal binding between seeing and hearing affective information. Neuroreport 11:1329-1333.

Pourtois G, de Gelder B, Bol A, Crommelinck M (2005) Perception of facial expressions and voices and of their combination in the human brain. Cortex 41:49-59.

Roebroeck A, Formisano E, Goebel R (2005) Mapping directed influence over the brain using Granger causality and fMRI. Neuroimage 25:230-242.

Ross LA, Saint-Amour D, Leavitt VM, Javitt DC, Foxe JJ (2007) Do you see what $\mathrm{i}$ am saying? Exploring visual enhancement of speech comprehension in noisy environments. Cereb Cortex 17:1147-1153.

Rossion B, Joyce CA, Cottrell GW, Tarr MJ (2003) Early lateralization and orientation tuning for face, word, and object processing in the visual cortex. Neuroimage 20:1609-1624.

Scherer KR (2003) Vocal communication of emotion: a review of research paradigms. Speech Comm 40:227-256.

Scherer KR, Banse R, Wallbott HG (2001) Emotion inferences from vocal expression correlate across languages and cultures. J Cross-Cult Psychol 32:76-92.

Schwartz JL, Berthommier F, Savariaux C (2004) Seeing to hear better: evidence for early audio-visual interactions in speech identification. Cognition 93:B69-B78.

Sekiyama K, Kanno I, Miura S, Sugita Y (2003) Auditory-visual speech perception examined by fMRI and PET. Neurosci Res 47:277-287.

Skipper JI, van Wassenhove V, Nusbaum HC, Small SL (2007) Hearing lips and seeing voices: how cortical areas supporting speech production mediate audiovisual speech perception. Cereb Cortex 17:2387-2399.

Sridharan D, Levitin DJ, Menon V (2008) A critical role for the right fronto-insular cortex in switching between central-executive and default-mode networks. Proc Natl Acad Sci USA 105:12569-12574.

Stephan KE, Roebroeck A (2012) A short history of causal modeling of fMRI data. Neuroimage 62:856-863.

Sumby WH, Pollack I (1954) Visual contribution to speech intelligibility in noise. J Acoust Soc Am 26:212-215. 
Szycik GR, Tausche P, Münte TF (2008) A novel approach to study audiovisual integration in speech perception: localizer fMRI and sparse sampling. Brain Res 1220:142-149.

Szycik GR, Jansma H, Münte TF (2009) Audiovisual integration during speech comprehension: an fMRI study comparing ROIbased and whole brain analyses. Hum Brain Mapp 30:1990-1999.

Szycik GR, Stadler J, Tempelmann C, Münte TF (2012) Examining the McGurk illusion using high-field 7 Tesla functional MRI. Front Hum Neurosci 6:95.

Talairach J, Tournoux P (1988) Co-planar stereotaxic atlas of the human brain. New York: Thieme Medical Publisher Inc..

Valdes-Sosa PA, Roebroeck A, Daunizeau J, Friston K (2011) Effective connectivity: influence, causality and biophysical modeling. Neuroimage 58:339-361.

Vo ML, Jacobs AM, Conrad M (2006) Cross-validating the Berlin affective word list. Behav Res Methods 38:606-609.

von Kriegstein K, Kleinschmidt A, Sterzer P, Giraud AL (2005) Interaction of face and voice areas during speaker recognition. $J$ Cogn Neurosci 17:367-376.
Vuilleumier P (2005) How brains beware: neural mechanisms of emotional attention. Trends Cogn Sci 9:585-594.

Vuilleumier P, Pourtois G (2007) Distributed and interactive brain mechanisms during emotion face perception: evidence from functional neuroimaging. Neuropsychologia 45:174-194.

Vuilleumier P, Armony JL, Driver J, Dolan RJ (2001) Effects of attention and emotion on face processing in the human brain: an event-related fMRI study. Neuron 30:829-841.

Wager TD, Phan KL, Liberzon I, Taylor SF (2003) Valence, gender, and lateralization of functional brain anatomy in emotion: a metaanalysis of findings from neuroimaging. Neuroimage 19:513-531. Whalen PJ, Shin LM, Mclnerney SC, Fischer H, Wright Cl, Rauch SL (2001) A functional MRI study of human amygdala responses to facial expressions of fear versus anger. Emotion 1:70-83.

Williams AC (2002) Facial expression of pain: an evolutionary account. Behav Brain Sci 25:439-455.

Wright TM, Pelphrey KA, Allison T, McKeown MJ, McCarthy G (2003) Polysensory interactions along lateral temporal regions evoked by audiovisual speech. Cereb Cortex 13:1034-1043. 